\title{
Research on Risk Formation Path of Coal Enterprises based on SEM Method
}

\author{
Yiyong Tang ${ }^{1 *}$, Wenxing $\mathrm{Li}^{1 *}$ \\ ${ }^{1}$ School of Economics and Management, Beijing Jiaotong University, China
}

\begin{abstract}
There are some problems in China's coal mining, such as limited mining technology, low degree of mechanization, lack of effective safety facilities, imperfect accident early warning mechanism and untimely response, which make the production safety problems perplex coal enterprises for a long time. This paper uses AMOS and SPSS 19.0 to analyze the coal risk data. The first is to establish the research hypotheses and conceptual model, set up structural equation model and path map. Secondly, the structural equation model and path coefficient are obtained by AMOS software, and the model is identified, evaluated and modified. Finally, the paper analyzes the direct effect and indirect effect between latent variables, latent variables and observed variables, and clarifies the risk factors of coal mining enterprises and the path of risk formation.
\end{abstract}

\section{Introduction}

As an important part of the energy structure in China, coal industry has created considerable economic benefits and provided huge employment space. At the same time, as a basic industry, it provides guarantee for the development of other industries. For the geological conditions and working environment in caol mining industry, production safety accidents often occur. In recent years, with the continuous development and improvement of coal marketing, coal enterprises have gradually changed their business model and organizational structure, but many risk managers still keep the old concept, and the risks faced by coal enterprises are increasing.

The existing risk management research is extremely lack of specific industries, and the actual risk characteristics of coal enterprises are also lack of detailed description. The existing research mainly focuses on the analysis of coal risk factors, but there are few deep-level problems, such as the path of risk formation, the causal relationship between risk factors and risk consequences, which all influence the scientifical and pracrical degree of the risk indentification in coal enterprises. This paper is going to clarify the main factors that affect the Chinese coal enterprises' risks, and the way how these factors lead to the safety risks of coal enterprises. This paper is going to clarify the main factors that affect the Chinese coal enterprises' risks, and the way how these factors lead to the safety risks of coal enterprises. In this paper, the basic situation of coal enterprise risk is investigated on the spot, the key risk factors are identified, and then the influencing factors are classified, and the basic hypothesis of the path relationship between risk factors is established. With the help of structural equation model, the formation path of coal enterprise risk is empirically studied.

\section{Questionnaire design and processing}

\subsection{Questionnaire design}

According to the research idea of structural equation modeling (SEM), the questionnaire was designed. (1) Basic information of investigators, (2) risk factors of coal enterprises. According to the endogenous and exogenous relationship, risk factors are divided into environmental factors, economic factors, technical factors, safety management factors, artificial factors and coal enterprise risk factors. At the same time, in order to facilitate collation, the six risk factors are classified into different observation variables, and the questionnaire of risk formation path of coal enterprises is designed accordingly.

Table 1. Variables explained in the questionnaire

\begin{tabular}{|l|l|}
\hline \multicolumn{1}{|c|}{ Risk factors } & \multicolumn{1}{c|}{ Observed variables } \\
\hline \multirow{4}{*}{ Environment $\left(\zeta_{1}\right)$} & Safety line $\left(\mathrm{Y}_{1}\right)$ \\
\cline { 2 - 2 } & Warning signs $\left(\mathrm{Y}_{2}\right)$ \\
\cline { 2 - 2 } & Mine environment $\left(\mathrm{Y}_{3}\right)$ \\
\hline \multirow{3}{*}{ Economic $\left(\eta_{1}\right)$} & Government interests $\left(\mathrm{Y}_{4}\right)$ \\
\cline { 2 - 2 } & Corporate interests $\left(\mathrm{Y}_{5}\right)$ \\
\cline { 2 - 2 } Technology $\left(\eta_{2}\right)$ & Corruption $\left(\mathrm{Y}_{6}\right)$ \\
\hline \multirow{3}{*}{} & Mechanization $\left(\mathrm{Y}_{7}\right)$ \\
\cline { 2 - 2 } & Security technology $\left(\mathrm{Y}_{8}\right)$ \\
\cline { 2 - 2 } & Safety equipment $\left(\mathrm{Y}_{9}\right)$ \\
\hline
\end{tabular}

\footnotetext{
* Corresponding author: 16113121@bjtu.edu.cn
} 


\begin{tabular}{|l|l|}
\hline \multirow{4}{*}{ Management $\left(\eta_{3}\right)$} & Safety training $\left(\mathrm{Y}_{10}\right)$ \\
\cline { 2 - 2 } & Safety system $\left(\mathrm{Y}_{11}\right)$ \\
\cline { 2 - 2 } & Emergency plan $\left(\mathrm{Y}_{12}\right)$ \\
\cline { 2 - 2 } & Operating procedures $\left(\mathrm{Y}_{13}\right)$ \\
\hline \multirow{4}{*}{ Artificial $\left(\eta_{4}\right)$} & Reaction capacity $\left(\mathrm{Y}_{14}\right)$ \\
\cline { 2 - 2 } & Safety consciousness $\left(\mathrm{Y}_{15}\right)$ \\
\cline { 2 - 2 } & Professional knowledge $\left(\mathrm{Y}_{16}\right)$ \\
\cline { 2 - 2 } Enterprise $\left(\eta_{5}\right)$ & Operation proficiency $\left(\mathrm{Y}_{17}\right)$ \\
\hline & Safety investment $\left(\mathrm{Y}_{18}\right)$ \\
\cline { 2 - 2 } & Safety level $\left(\mathrm{Y}_{19}\right)$ \\
\hline
\end{tabular}

\subsection{Questionnaire data processing}

Through the way of pre survey quota, 50 questionnaires were distributed first. According to the results of the pre survey, the total variance of the sample is $1.513, \mathrm{~d}=0.2$, when the confidence level is $95 \%, z=1.94$, the calculation can get 150.23 , according to the condition of design effect deff $>1$, deff $=2$ can be taken. The final sample size is 299.22 , and the sample size can be determined to be 300 , which also meets the requirement of SEM that the relationship between sample size and observation index number is $\mathrm{N} / \mathrm{P}>10$.

The validity of the questionnaire mainly measures the authenticity of theoretical ideas or traits. The validity of the questionnaire was analyzed by spss19.0, and Bartlett's test results were significant (significance $=$. $000), \mathrm{kmo}=0.788>0.5$, indicating that the validity of the questionnaire was good.

\section{Model definition}

\subsection{Structural model hypothesis}

The hypothesis of structural equation model is the basic premise of the research. According to the actual research and references, the basic hypothesis of the relationship between the latent variables is made. Based on this, the formation path of coal risk is established, and the hypothesis is verified by structural equation model.

H1: "environmental factors" of coal enterprises will have a certain impact on "economy", "technology", "safety management" and "artificial".

H2: "economic factors" of coal enterprises will have a certain impact on "technology", "safety management" and "artificial".

H3: "technical factors" of coal enterprises will have a certain impact on "safety management" and "artificial".

H4: "safety management factors" of coal enterprises will have a certain impact on "artificial".

\subsection{Risk formation path of coal enterprises}

According to the research hypothesis, the structural relationship is established. Then we can draw the formation path map of the risk theoretical model of Chinese coal enterprises, and estimate the parameters of the risk model of coal enterprises by using the estimation method of SEM adaptation function. Figure 1-1 shows the relationship among environment, economy, technology, safety management and artificial factors, as well as the action path and parameter estimation that affect the risk of coal enterprises.

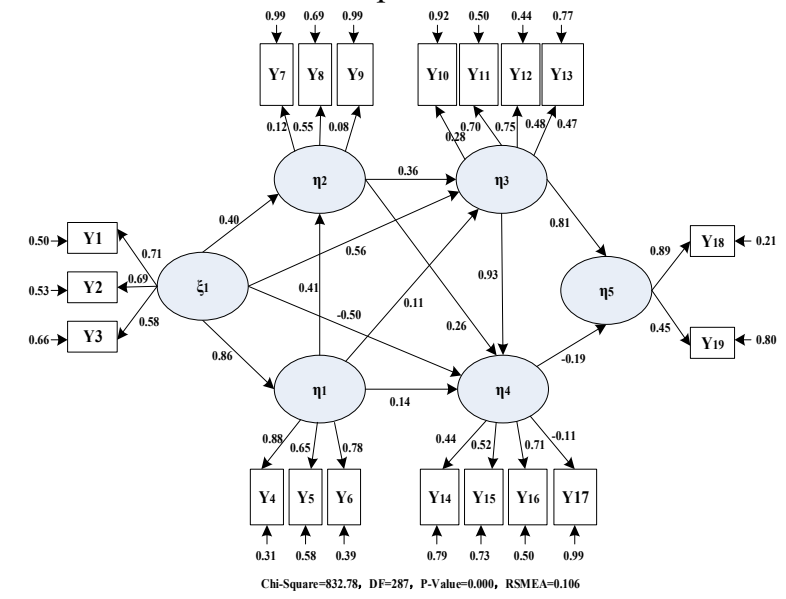

Fig. 1. The basic model of the initial model (the standard parameter estimation)

\section{Model interpretation}

Structural equation model aims to reveal the relationship between variables through path coefficient and factor load coefficient. Path coefficient refers to the regression coefficient between latent variables and latent variables, and factor load coefficient refers to the regression coefficient between latent variables and observed variables. The effect of the research model can be divided into direct effect, indirect effect and total effect. Direct effect refers to the influence of cause variables on result variables, without any other intermediate variables. Indirect effect refers to the influence of cause variables on result variables by influencing several intermediate variables. The total effect is the sum of direct effect and indirect effect.

In structural equation modeling, $A_{x}, A_{y}, B$ and $\Gamma$ are the influence matrix between latent variables. The load coefficient $\left(\lambda_{x}\right)$ in the $A_{x}$ matrix is the direct effect of exogenous latent variables on exogenous observed variables; the load coefficient $\left(\lambda_{y}\right)$ in the $A_{y}$ matrix is the direct effect of endogenous latent variables on endogenous observed variables; the structure coefficient $(\beta)$ in the B matrix is the basic direct effect between endogenous latent variables; the structure coefficient $(\gamma)$ in the $\Gamma$ matrix is the basic direct effect of exogenous latent variables on endogenous latent variables .

In addition, Cohen (1988) proposed a criterion for the influence of coefficient. For the standardized path coefficient, its absolute value less than 0.10 is a small effect, its absolute value about 0.30 is a medium effect, and its absolute value above 0.50 is a large effect.

Table 2. Direct effects between latent variables

\begin{tabular}{|c|c|c|c|c|}
\hline Influence & Eff. Value & Std. Err & $\mathbf{t}$ & Std.Value \\
\hline$\xi_{1} \rightarrow \eta_{1}$ & 1.13 & 0.15 & $7.70^{*}$ & 0.88 \\
\hline$\xi_{1} \rightarrow \eta_{2}$ & 0.44 & 0.39 & 1.13 & 0.36 \\
\hline
\end{tabular}




\begin{tabular}{|c|c|c|c|c|}
\hline$\xi_{1} \rightarrow \eta_{3}$ & 0.41 & 0.20 & $2.06^{*}$ & 0.60 \\
\hline$\xi_{1} \rightarrow \eta_{4}$ & -0.87 & 0.73 & -1.19 & -1.00 \\
\hline$\eta_{1} \rightarrow \eta_{2}$ & 0.43 & 0.29 & 1.49 & 0.46 \\
\hline$\eta_{1} \rightarrow \eta_{3}$ & 0.04 & 0.13 & 0.30 & 0.07 \\
\hline$\eta_{1} \rightarrow \eta_{4}$ & 0.16 & 0.28 & 0.55 & 0.23 \\
\hline$\eta_{2} \rightarrow \eta_{3}$ & 0.18 & 0.11 & 1.65 & 0.33 \\
\hline$\eta_{2} \rightarrow \eta_{4}$ & 0.11 & 0.29 & 0.38 & 0.16 \\
\hline$\eta_{3} \rightarrow \eta_{4}$ & 1.25 & 1.07 & 1.16 & 0.97 \\
\hline$\eta_{3} \rightarrow \eta_{5}$ & 1.79 & 0.47 & $3.80^{*}$ & 0.82 \\
\hline$\eta_{4} \rightarrow \eta_{5}$ & -0.34 & 0.16 & -2.09 & -0.20 \\
\hline
\end{tabular}
$* p<0.05$

Table 3. Indirect effects between latent variables

\begin{tabular}{|c|c|c|c|c|}
\hline Influence & Eff. Value & Std. Err & $\mathbf{t}$ & Std.Value \\
\hline$\xi_{1} \rightarrow \eta_{2}$ & 0.49 & 0.33 & 1.51 & 0.40 \\
\hline$\xi_{1} \rightarrow \eta_{3}$ & 0.21 & 0.15 & 1.42 & 0.31 \\
\hline$\xi_{1} \rightarrow \eta_{4}$ & 1.06 & 0.73 & 1.45 & .1 .22 \\
\hline$\xi_{1} \rightarrow \eta_{5}$ & 1.04 & 0.14 & $7.31^{*}$ & 0.71 \\
\hline$\eta_{1} \rightarrow \eta_{3}$ & 0.08 & 0.08 & 0.99 & 0.15 \\
\hline$\eta_{1} \rightarrow \eta_{4}$ & 0.19 & 0.17 & 1.13 & 0.29 \\
\hline$\eta_{1} \rightarrow \eta_{5}$ & 0.09 & 0.24 & 0.36 & 0.08 \\
\hline$\eta_{2} \rightarrow \eta_{4}$ & 0.23 & 0.21 & 1.08 & 0.32 \\
\hline$\eta_{2} \rightarrow \eta_{5}$ & 0.21 & 0.17 & 1.21 & 0.17 \\
\hline$\eta_{3} \rightarrow \eta_{5}$ & -0.43 & 0.43 & -0.99 & -0.20 \\
\hline$* p<0.05$ & & &
\end{tabular}

Table 4. The total effect between latent variables

\begin{tabular}{|c|c|c|c|c|}
\hline Influence & Eff. Value & Std. Err & $\mathbf{t}$ & Std.Value \\
\hline$\xi_{1} \rightarrow \eta_{1}$ & 1.13 & 0.15 & $7.70^{*}$ & 0.88 \\
\hline$\xi_{1} \rightarrow \eta_{2}$ & 0.94 & 0.16 & $6.01^{*}$ & 0.77 \\
\hline$\xi_{1} \rightarrow \eta_{3}$ & 0.62 & 0.17 & $3.69^{*}$ & 0.92 \\
\hline$\xi_{1} \rightarrow \eta_{4}$ & 0.19 & 0.11 & 1.75 & 0.22 \\
\hline$\xi_{1} \rightarrow \eta_{5}$ & 1.04 & 0.14 & $7.31^{*}$ & 0.71 \\
\hline$\eta_{1} \rightarrow \eta_{2}$ & 0.43 & 0.29 & 1.49 & 0.46 \\
\hline$\eta_{1} \rightarrow \eta_{3}$ & 0.12 & 0.13 & 0.89 & 0.22 \\
\hline$\eta_{1} \rightarrow \eta_{4}$ & 0.35 & 0.26 & 1.35 & 0.52 \\
\hline$\eta_{1} \rightarrow \eta_{5}$ & 0.09 & 0.24 & 0.36 & 0.08 \\
\hline$\eta_{2} \rightarrow \eta_{3}$ & 0.18 & 0.11 & 1.65 & 0.33 \\
\hline$\eta_{2} \rightarrow \eta_{4}$ & 0.34 & 0.23 & 1.44 & 0.47 \\
\hline$\eta_{2} \rightarrow \eta_{5}$ & 0.21 & 0.17 & 1.21 & 0.17 \\
\hline$\eta_{3} \rightarrow \eta_{4}$ & 1.25 & 1.07 & 1.16 & 0.97 \\
\hline$\eta_{3} \rightarrow \eta_{5}$ & 1.36 & 0.52 & $2.61^{*}$ & 0.62 \\
\hline$\eta_{4} \rightarrow \eta_{5}$ & -0.34 & 0.16 & -2.09 & -0.20 \\
\hline$* p<0.05$ & & & & \\
\hline
\end{tabular}

\subsection{Environmental factors}

It can be seen from the above table that "environmental factors" have significant effects on "economic factors", "technical factors", "safety management factors" and "enterprise risk", and the total effect values are 0.88 , $0.77,0.92$ and 0.71 respectively, which are all large effects $(>0.5)$. It shows that the reasonable setting of environmental factors plays an obvious role in the safety management and risk prevention of coal enterprises. When other conditions remain unchanged, the latent variable of "environmental factor" increases by 1 unit, the latent variables of "economic factor", "technical factor", "safety management factor" and "enterprise risk" will be increased by $0.88,0.77,0.92$ and 0.71 units respectively.

The direct effect coefficient of "environmental factors" on "artificial factors" was negative (-1.00). It shows that the relationship between them is reverse. In other words, the safety behavior of coal enterprise workers plays a great role in promoting the improvement of environmental factors, rather than that the improvement of environmental factors promotes the safety behavior of coal enterprise workers.

\subsection{Economic factors}

The total effect value of "economic factor" on "technical factor" and "artificial factors" is 0.46 and 0.52 respectively, which is close to or belongs to large effect. It shows that the interests of the main body in economic factors have an important impact on the safety level of technological factors and the safety behavior of coal enterprise workers. But the significance of the parameters is not very high.

The total effect value of "economic factors" on "safety management factors" is not large and the significance is not high, which is 0.22 and 0.89 respectively. The direct effect $(0.07)$ is much lower than the indirect effect $(0.15)$ when technical factors are intermediate variables. It shows that the theoretical hypothesis that "economic interests have a very important impact on "safety management factors" has not been confirmed. This is quite different from the theoretical hypothesis, but there are also internal reasons. It is not necessarily very effective for the local government to send the supervision team to the scene of coal enterprises for safety inspection. On the contrary, the most effective measure is to establish and improve the safety laws and regulations system and safety management and supervision mechanism.

\subsection{Technical factors}

The direct effect of "technical factors" on "safety management factors", that is, the total effect is 0.33 , which belongs to medium effect. It shows that technical factors have an important impact on the safety management behavior of coal enterprises. And the effect of technical factors on the safety management behavior of coal enterprises is greater than the direct effect $(0.07)$ 
and the total effect value $(0.22)$ of economic factors on the safety management factors of coal enterprises.

This shows the important role of technical factors in the safety production management of coal enterprises, and also implies that the focus of coal mine safety investment is not safety management, but to improve science and technology.

\subsection{Management factors}

"Safety Management factor" has a significant impact on "enterprise risk" avoidance, and its direct effect is 0.82 . It shows that the safety management of coal enterprises plays an important role in the safety risk avoidance and prevention of coal enterprises.

The total effect value of "safety management factors" on "artificial factors" is 0.97 , which belongs to the large effect value. The theoretical hypothesis that "good safety management factors of coal enterprises have an important impact on miners' safety production behavior" has also been confirmed. The effect of coal enterprises on miners is also the largest among all kinds of effects on coal enterprise workers, It shows that the safety education and training, emergency plan and other behaviors of coal enterprises have a decisive impact on the safety production behavior and risk aversion behavior of coal mine employees.

\subsection{Artificial factors}

The effect value of "artificial factors" on "enterprise risk factors" is 0.20 , the value is -2.09 . It shows that coal enterprise employees have a certain impact on coal mine safety risk aversion. However, from the existing data, this kind of impact is a negative impact: low quality, lack of professional knowledge, illegal operation and other unsafe behaviors are the direct causes of risk accidents in coal enterprises.

The effect value of coal enterprise safety management on avoiding "enterprise risk" is far greater than that of miners on avoiding "enterprise risk", which indicates that the coal enterprise level plays a greater role in the two main levels that directly affect the safety of coal enterprises.

\section{Conclusion}

The analysis of the model results shows that the main theoretical assumptions of the theoretical model of this study have been confirmed. Economic development and technology upgrading are the fundamental driving force for coal enterprises to avoid and prevent risks. Under the promotion of this force, enterprise safety management and human safety behavior are constantly strengthened, and become the middle force of risk aversion in coal enterprises. Coal enterprise is the most important direct subject of coal mine safety production, and its safety management behavior is affected by various forces.

\section{Acknowledgments}

This work was financially supported by Beijing Philosophy and Social Science Planning Fund Project, project number 17JDYJB006, and by National Development and Reform Commission, project number B19DR00010.

\section{References}

1. Hao S L , Ding Z X . Design of Internal Control Risk Management System of Coal Mining Enterprises Based on Systems Engineering[J]. Advanced Materials Research, (2012).

2. Xiao J , Zhang J , Liu C . The Research on Financial Risk Management of Large State-Owned Coal Enterprises[J]. Industrial Safety \& Environmental Protection, (2010).

3. Timofeeva S S, Murzin M A . Man-made risks of coal mining enterprises[J]. IOP Conference Series: Earth and Environmental Science, (2019).

4. Tomasz, Leszek, Nawrocki, et al. Assessing operational risk in coal mining enterprises Internal, industrial and international perspectives[J]. Resources Policy, (2016)

5. Wu Y, Liu L, Zhou J, et al. Research on optimization of hedging ratio of thermal coal futures in thermal power enterprises based on Delphi method[J]. Energy Systems, (2019).

6. Cohen J, Cohen J , Cohen J W, et al. Statistical power analysis for the behavioral science[J]. Technometrics, 31,(1988).

7. Nelson, et al. "Environmental impacts of coal combustion: A risk approach to assessment of emissions." FUEL -GUILDFORD- (2010).

8. Onur, et al. "A semi-quantitative coal burst risk classification system." International Journal of Mining Science \& Technology (2018).

9. Li, H. T. . "Probe into the Safety Management of Coal Enterprises According to Modern Firm Theory." CHINA SAFETY SCIENCE JOURNAL(1999). 